\title{
PEMERIKSAAN KESESUAIAN KRITERIA FUNGSI JALAN DAN KONDISI GEOMETRIK SIMPANG AKIBAT PERUBAHAN DIMENSI KENDARAAN RENCANA
}

\author{
Angga Marditama Sultan Sufanir \\ Dosen / Jurusan Teknik Sipil / Politeknik Negeri Bandung \\ Jl. Gegerkalong Hilir, Ds. Ciwaruga, Bandung 40012 \\ E-mail: angga.mss@polban.ac.id
}

\begin{abstract}
Arterial, collector, and local are the hierarchy of road function in urban areas. Each of them is composed by primary and secondary road network. Certain road functions have certain criterion. Those criterion help in determining the type of design vehicle. Dimensionals and turning radius of the design vehicle are related to road geometric, i.e. the lane width and the widening of horizontal curve and intersection. The aim of this research is to check the suitability of road function criterion with the intersection geometric condition at Dipatiukur and Hasanuddin streets in Bandung. Those streets are chosen because they experience a change of the design vehicle dimension. Dipatiukur street has a secondary collector function, while Hasanuddin street has a secondary local function. Pd.T-18-2004-B, the guideline about a determination of road function classification in urban areas, stated that bus is not permitted to get through a local secondary road. In fact, DAMRI bus line 7 can get through Hasanuddin street. The result of checking the suitability of road function criterion can be seen from both design speed and the width of the road. If the vehicle designed is a car, it can be concluded that those two streets meet the requirements. Meanwhile, the result of checking the intersection geometric condition shows that the turning radius, entering sight distance, and the path for a bus are not appropriate with Pt.T 02-2002-B guideline about a Geometric Intersection Designing Procedure and a Geometric Designing Procedure for Inter-Urban Road Numb. 038/TBM/1997.
\end{abstract}

Keywords : design vehicle, intersection geometric, turning radius.

\section{PENDAHULUAN}

Kota Bandung memiliki jumlah penduduk sebanyak 2.470 .802 jiwa, panjang jalan $1.237 \mathrm{~km}$, jumlah kendaraan bermotor sebanyak 1.443.217 unit dan $98 \%$ merupakan kendaraan pribadi (BPS Kota Bandung Dalam Angka, 2015). Banyaknya jumlah kendaraan bermotor menimbulkan permasalahan sistem transportasi perkotaan, diantaranya: kemacetan, parkir, polusi udara dan suara, dan pemborosan penggunaan energi. Untuk mengatasi permasalahan tersebut, perlu dioperasikan Sarana Angkutan Umum Massal (SAUM) yang mampu mengangkut penumpang dengan jumlah banyak dan terjadwal. Perum DAMRI Cabang Bandung mengoperasikan beberapa trayek bus dalam kota, salah satunya jalur 07 Dipatiukur - Jatinangor. Pengoperasian Bus DAMRI jalur 07 ini tidak diimbangin dengan peningkatan prasarana jalan, hal ini dapat dilihat dari rutenya yang melintasi Jalan Hasanuddin. Berdasarkan daftar ruas jalan menurut hirarki yang didapat dari Dinas Bina Marga Kota Bandung tahun 2014, Jalan Dipatiukur memiliki fungsi kolektor sekunder dan Jalan Hasanuddin memiliki fungsi lokal sekunder. Menurut Pedoman dari Departemen Permukiman dan Prasarana Wilayah Pd.T-18-2004-B tentang Penentuan Klasifikasi Fungsi Jalan di Kawasan Perkotaan, bus tidak diijinkan untuk melintasi jalan lokal sekunder. Tujuan dari penelitian ini yaitu memeriksa kesesuaian kriteria fungsi jalan dan kondisi geometrik simpang akibat perubahan dimensi kendaraan rencana pada Simpang Jalan Dipatiukur - Jalan Hasanuddin di Kota Bandung. 


\section{TINJAUAN PUSTAKA}

Menurut UU Republik Indonesia No. 38 tahun 2004, jalan merupakan prasarana transportasi darat yang meliputi segala bagian jalan, bangunan pelengkap, dan perlengkapannya yang diperuntukkan bagi lalu lintas, permukaan tanah, di atas permukaan tanah, di bawah permukaan tanah dan atau air, serta di atas permukaan air, kecuali jalan kereta api dan jalan kabel. Bagian-bagian dari jalan terdiri dari:

a. Ruang Manfaat Jalan (RUMAJA) meliputi badan jalan dan bangunan pelengkapnya.

b. Ruang Milik Jalan (RUMIJA) meliputi RUMAJA dan sejalur tanah tertentu di luar RUMAJA.

c. Ruang Pengawasan Jalan (RUWASJA) merupakan ruang tertentu di luar RUMIJA yang ada di bawah pengawasan penyelenggara jalan.

Klasifikasi fungsi jalan berdasarkan Pd.T-18-2004-B, terdiri dari:

a. Jalan arteri primer dan arteri sekunder.

b. Jalan kolektor primer dan kolektor sekunder.

c. Jalan lokal primer dan lokal sekunder. Jalan kolektor sekunder didesain berdasarkan kecepatan rencana paling rendah $20 \mathrm{~km} / \mathrm{jam}$, lebar badan jalan minimal 9 meter, harus mempunyai perlengkapan jalan yang cukup, serta besarnya LHR pada umumnya lebih rendah dari sistem primer dan arteri sekunder. Ciri-ciri jalan kolektor sekunder yaitu: menghubungkan antar kawasan sekunder kedua dan menghubungkan kawasan sekunder kedua dengan kawasan sekunder ketiga, kendaraan angkutan barang berat tidak diijinkan melintas, lokasi parkir pada badan jalan dibatasi.

Jalan lokal sekunder didesain berdasarkan kecepatan rencana paling rendah $10 \mathrm{~km} / \mathrm{jam}$, lebar badan jalan minimal 6,5 meter, serta besarnya LHR pada umumnya paling rendah dibandingkan dengan fungsi jalan lain. Ciri-ciri jalan lokal sekunder yaitu: menghubungkan antara kawasan sekunder ketiga atau dibawahnya dan menghubungkan kawasan sekunder dengan perumahan, kendaraan angkutan berat dan bus tidak diijinkan melintas.

Dalam perencanaan teknis geometrik jalan, setiap kelompok jenis kendaraan diwakili oleh satu ukuran standar yang disebut "Kendaraan Rencana". Kendaraan rencana sebagai parameter perancangan teknis jalan, akan mengikat semua rancangan unsur geometrik jalan yang dihasilkan. Setiap unsur geometrik jalan harus bisa memenuhi pergerakan kendaraan sesuai kecepatan rencana, bisa memberikan keselamatan, kelancaran, dan kenyamanan. Kendaraan rencana ditentukan berdasarkan fungsi jalan yang bersangkutan. (Kusnandar E., 2008)

Unsur teknis kendaraan rencana berkaitan langsung dengan unsur geometrik jalan, diantaranya:

a. Dimensi kendaraan, mempengaruhi lebar lajur.

b. Jari-jari putar (turning radius) minimum, mempengaruhi pelebaran lajur di tikungan dan pola lintasan (turning path) di tikungan/ persimpangan.

c. Jari-jari putar, mempengaruhi lebar median pada saat kendaraan melakukan putaran balik arah (U-turn).

Ditjen Bina Marga dalam buku Tata Cara Perencanaan Geometrik Jalan antar Kota No. 038/TBM/1997, menetapkan dimensi kendaraan rencana seperti tersaji pada Tabel 1.

Departemen Perhubungan mengeluarkan kebijakan operasional lalu lintas yang tercantum dalam UU Republik Indonesia No. 22 tahun 2009 tentang Lalu Lintas dan Angkutan Jalan dalam pasal 19 ayat 2 menetapkan bahwa kelas jalan dan dimensi kendaraan bermotor yang harus mampu ditampung, disajikan pada Tabel 2.

Perubahan dimensi kendaraan rencana menjadi lebih besar menuntut perubahan geometrik, hal ini berkaitan dengan lebar jalan serta jari-jari putar di tikungan dan persimpangan (Iskandar H., 2008). 
Tabel 1. Dimensi kendaraan rencana

\begin{tabular}{lrrrrrrrr}
\hline Jenis Kendaraan & \multicolumn{7}{c}{ Panjang Unsur Teknis Kendaraan (meter) } \\
\cline { 2 - 9 } & Panjang & Lebar & Tinggi & $\begin{array}{c}\text { Tonjolan } \\
\text { Depan }\end{array}$ & Jarak Gandar & $\begin{array}{c}\text { Tonjolan } \\
\text { Belakang }\end{array}$ & $\begin{array}{c}\text { Jari-jari } \\
\text { Putar }\end{array}$ \\
\hline Mobil Penumpang & 5,80 & 2,10 & 1,30 & 0,90 & 3,40 & 1,50 & 7,30 \\
\hline Truk & 12,10 & 2,60 & 4,10 & 2,10 & 7,60 & 2,40 & 12,80 \\
\hline Bus & 12,10 & 2,60 & 4,10 & 2,10 & 7,60 & 2,40 & 12,00 \\
\hline Trailer & 21,00 & 2,60 & 4,10 & 1,20 & $\begin{array}{r}4,00 \text { (depan) } \\
9,00\end{array}$ & 0,90 & 12,00 \\
\hline
\end{tabular}

Sumber: Tata Cara Perencanaan Geometrik Jalan antar Kota No. 038/TBM/1997

Tabel 2. Kelas jalan dan dimensi kendaraan bermotor

\begin{tabular}{|c|c|c|c|c|c|}
\hline \multirow[t]{2}{*}{ Kelas Jalan } & \multirow[t]{2}{*}{ Fungsi Jalan } & \multicolumn{4}{|c|}{$\begin{array}{c}\text { Dimensi dan MST Kendaraan Bermotor } \\
\text { yang harus mampu ditampung }\end{array}$} \\
\hline & & $\begin{array}{c}\text { Lebar } \\
\text { (meter) }\end{array}$ & $\begin{array}{c}\text { Panjang } \\
\text { (meter) }\end{array}$ & $\begin{array}{l}\text { MST } \\
\text { (ton) }\end{array}$ & $\begin{array}{l}\text { Tinggi } \\
\text { (meter) }\end{array}$ \\
\hline Khusus & Arteri & $\geq 2,50$ & $\geq 18,00$ & $\geq 10$ & $\leq 4,20$ \\
\hline $\mathrm{I}$ & Arteri, Kolektor & $\leq 2,50$ & $\leq 18,00$ & $\leq 10$ & $\leq 4,20$ \\
\hline II & Arteri, Kolektor, Lokal, dan Lingkungan & $\leq 2,50$ & $\leq 12,00$ & $\leq 8$ & $\leq 4,20$ \\
\hline III & Arteri, Kolektor, Lokal, dan Lingkungan & $\leq 2,10$ & $\leq 9,00$ & $\leq 8$ & $\leq 3,50$ \\
\hline
\end{tabular}

Sumber: UU Republik Indonesia No. 22 tahun 2009 tentang Lalu Lintas dan Angkutan Jalan

Tabel 3. Kecepatan rencana dan lebar badan jalan eksisting

\begin{tabular}{cccccrr}
\hline \multirow{2}{*}{ No. } & Nama Ruas & \multirow{2}{*}{ Fungsi } & \multicolumn{2}{c}{ Kecepatan Rencana } & \multicolumn{2}{c}{ Lebar Badan Jalan } \\
\cline { 3 - 6 } & & & Pd.T 18-2004-B & Eksisting* & Pd.T 18-2004-B & Eksisting \\
\hline 1 & Jl. Dipatiukur & Kolektor Sekunder & $\geq 20 \mathrm{~km} / \mathrm{jam}$ & $40 \mathrm{~km} / \mathrm{jam}$ & $\geq 9,0 \mathrm{~m}$ & $10 \mathrm{~m}$ \\
\hline 2 & Jl. Hasanuddin & Lokal Sekunder & $\geq 10 \mathrm{~km} / \mathrm{jam}$ & $20 \mathrm{~km} / \mathrm{jam}$ & $\geq 6,5 \mathrm{~m}$ & $8 \mathrm{~m}$ \\
\hline
\end{tabular}

\section{METODOLOGI PENELITIAN}

Pengumpulan data dilaksanakan dengan cara survai primer dan sekunder, kemudian data hasil survai dianalisis sesuai dengan tata cara/ pedoman yang berlaku dan disimpulkan hasilnya. Survai-survai yang telah dilaksanakan, diantaranya:

a. Klasifikasi fungsi jalan sesuai dengan Pd.T 18-2004-B tentang Penentuan Klasifikasi Fungsi Jalan di Kawasan Perkotaan.

b. Lebar badan jalan sesuai dengan Tata Cara Pelaksanaan Survai Inventarisasi Jalan dan Jembatan Kota No. 017/T/BNKT/1990.

c. Kecepatan kendaraan sesuai dengan Panduan Survai dan Perhitungan Waktu Perjalanan Lalu Lintas No. 001/T/BNKT/1990.

d. Dimensi kendaraan rencana sesuai dengan Tata Cara Perencanaan Geometrik Jalan antar Kota No. 038/TBM/1997 dan UU Republik Indonesia No. 22 tahun 2009 tentang Lalu Lintas dan Angkutan Jalan dalam pasal 19 ayat 2 .

e. Jari-jari putar dan pola lintasan kendaraan sesuai dengan Tata Cara Perencanaan Geometrik Jalan antar Kota No. 038/TBM/1997.

f. Jarak pandang masuk sesuai dengan Pt.T 02-2002-B Tata Cara Perencanaan Geometrik Persimpangan Sebidang.

\section{HASIL DAN PEMBAHASAN}

Jalan Dipatiukur memiliki fungsi kolektor sekunder dan Jalan Hasanuddin memiliki fungsi lokal sekunder. Berdasarkan kriteria fungsi jalan, dilihat dari parameter kecepatan rencana dan lebar badan jalan eksisting memenuhi persyaratan Pd.T 18-2004-B, disajikan pada Tabel 3.

Pd.T 18-2004-B mensyaratkan bahwa kendaraan rencana untuk jalan dengan fungsi kolektor sekunder dan lokal sekunder yaitu mobil penumpang, sedangkan pada kenyataannya bus melintasi jalan tersebut. Dimensi mobil penumpang dan bus menurut Tata Cara Perencanaan Geometrik Jalan antar Kota No. 038/TBM/1997, dapat dilihat pada Gambar 1. 
Untuk memeriksa apakah kondisi geometrik Simpang Jalan Dipatiukur - Jalan Hasanuddin mampu dilintasi kendaraan rencana berupa bus yang dimensinya lebih besar dari mobil penumpang, maka perlu dilakukan serangkaian pemeriksaan seperti tersaji pada Tabel 4. Dengan jari-jari tikungan eksisting sebesar 7,8 meter, mobil penumpang masih bisa berbelok ke Jalan Hasanuddin tanpa mengganggu arus lalu lintas dari arah sebaliknya (Gambar 2). Perubahan kendaraan rencana ke dimensi yang lebih besar, dalam hal ini dari mobil penumpang menjadi bus, memerlukan perubahan jari-jari tikungan dan pelebaran lajur di persimpangan (Gambar 3).
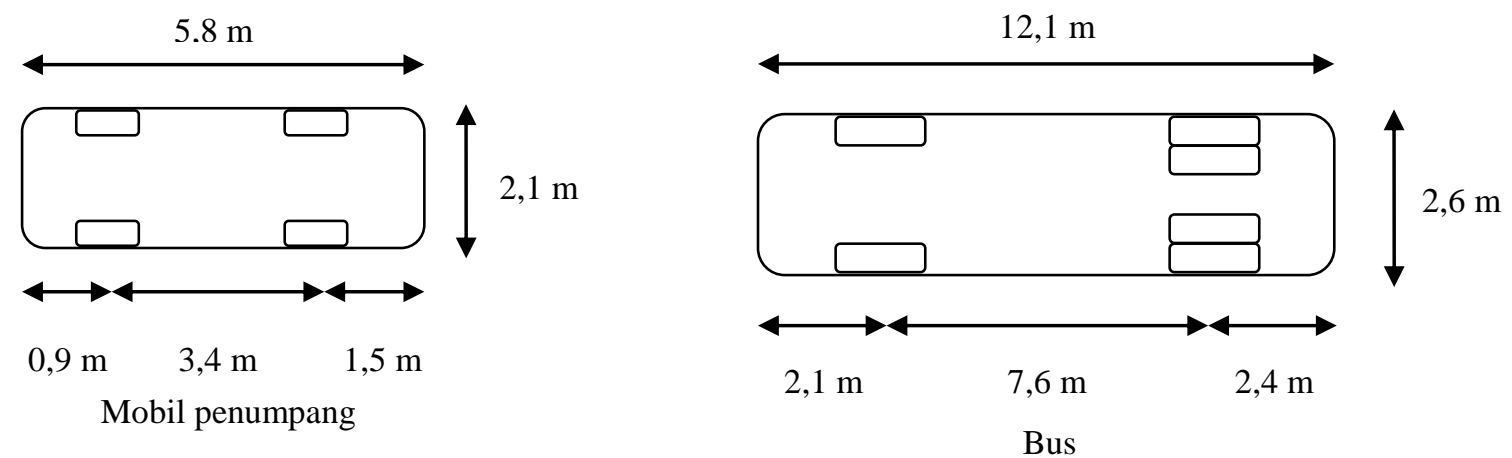

Gambar 1. Dimensi mobil penumpang dan bus

Tabel 4. Pemeriksaan kesesuaian unsur teknis

\begin{tabular}{|c|c|c|c|c|c|c|}
\hline \multirow[t]{2}{*}{ No. } & \multirow[t]{2}{*}{ Unsur Teknis } & \multirow[t]{2}{*}{ Eksisting } & \multirow[t]{2}{*}{ Minimum } & \multirow[t]{2}{*}{ Pedoman } & \multicolumn{2}{|c|}{ Pemeriksaan } \\
\hline & & & & & Sesuai & Tidak Sesuai \\
\hline 1 & Jari-jari putar & $7,8 \mathrm{~m}$ & $15 \mathrm{~m}$ & $\begin{array}{l}\text { Tata Cara Perencanaan } \\
\text { Geometrik Jalan antar Kota } \\
\text { No. 038/TBM/1997 }\end{array}$ & & $\mathrm{X}$ \\
\hline 2 & Jarak pandang masuk & $19,2 \mathrm{~m}$ & $30 \mathrm{~m}$ & $\begin{array}{l}\text { Pt.T 02-2002-B Tata Cara } \\
\text { Perencanaan Geometrik } \\
\text { Persimpangan Sebidang }\end{array}$ & & $\mathrm{X}$ \\
\hline 3 & $\begin{array}{l}\text { Pola lintasan Mobil } \\
\text { Penumpang }\end{array}$ & Gam & bar 2 & $\begin{array}{l}\text { Tata Cara Perencanaan } \\
\text { Geometrik Jalan antar Kota } \\
\text { No. 038/TBM/1997 }\end{array}$ & $\mathrm{X}$ & \\
\hline 4 & Pola lintasan Bus & Gam & bar 3 & $\begin{array}{l}\text { Tata Cara Perencanaan } \\
\text { Geometrik Jalan antar Kota } \\
\text { No. 038/TBM/1997 }\end{array}$ & & $\mathrm{X}$ \\
\hline
\end{tabular}




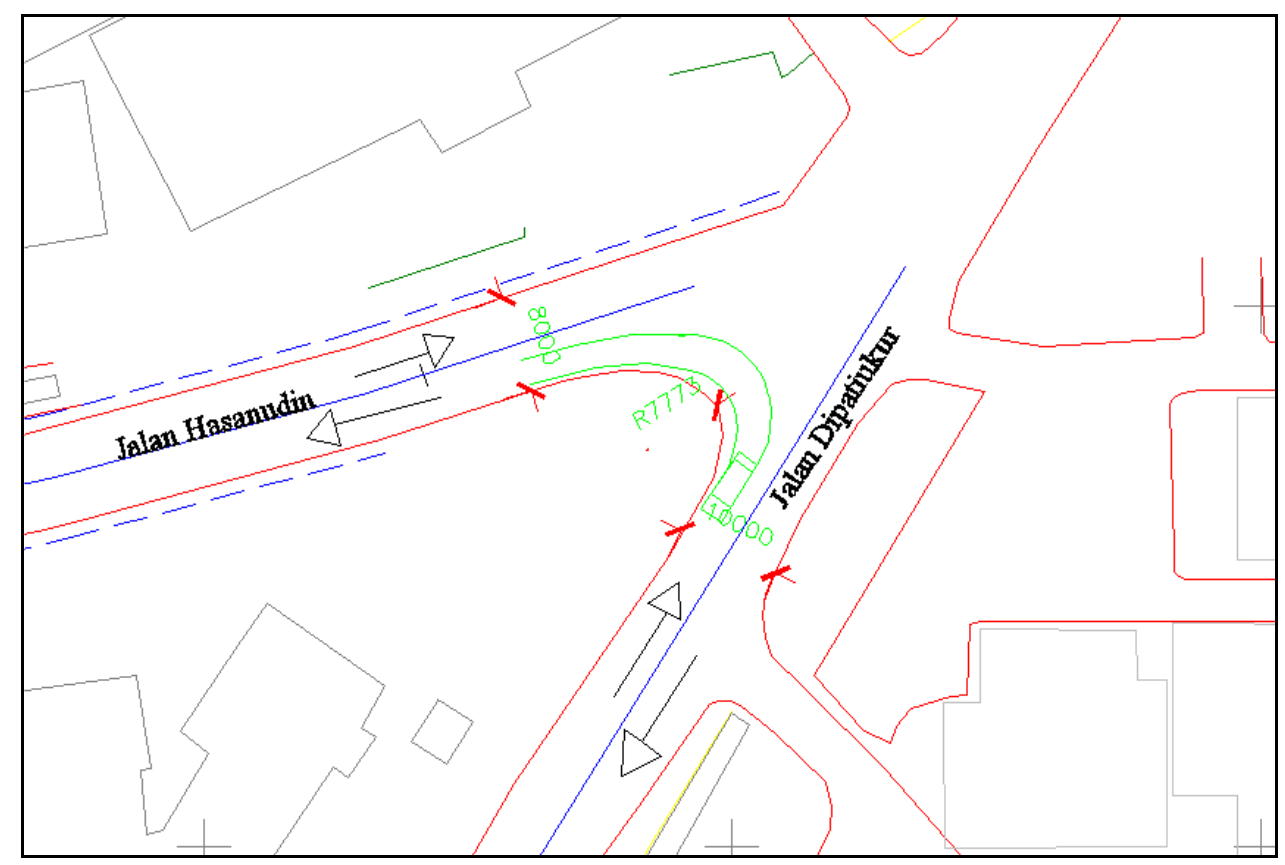

Gambar 2. Pola lintasan mobil penumpang

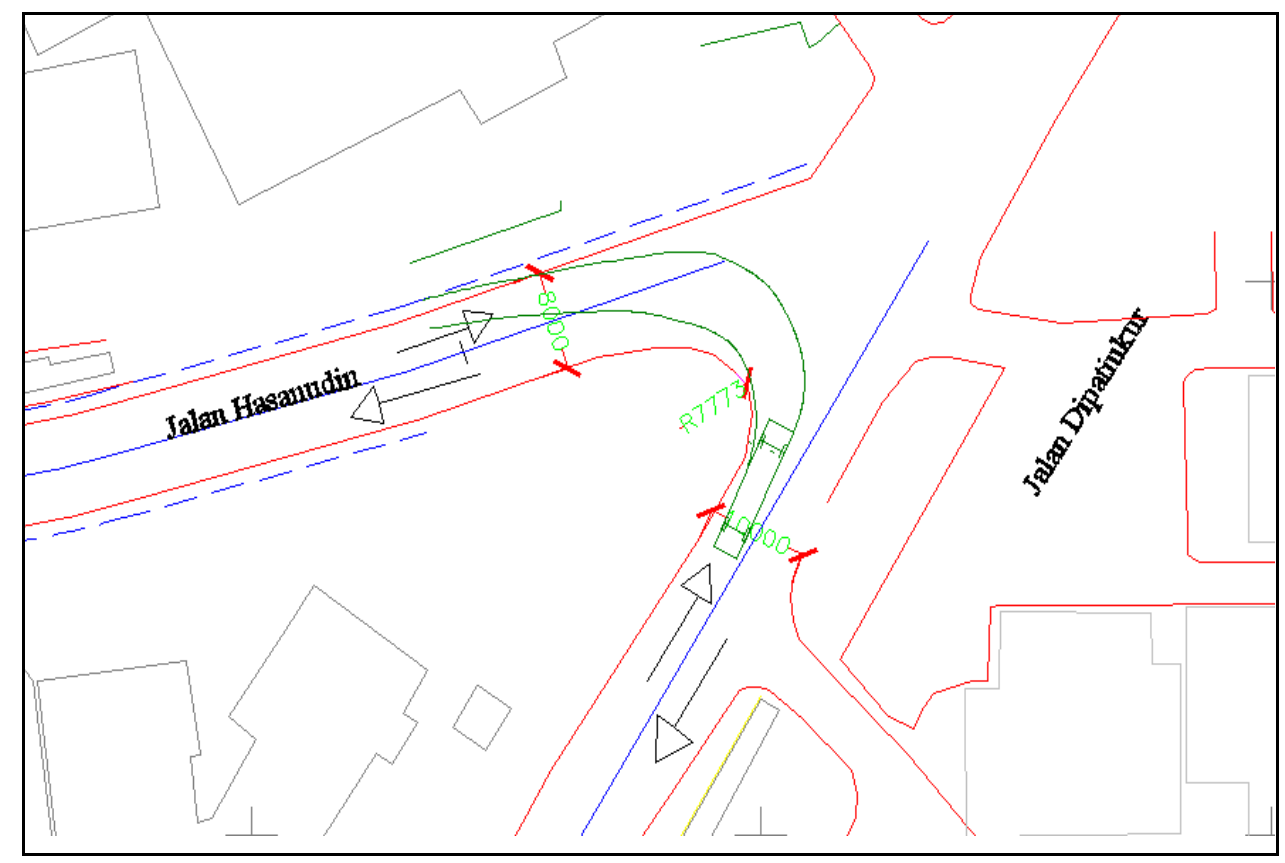

Gambar 3. Pola lintasan bus

\section{KESIMPULAN DAN SARAN}

Kesimpulan yang dapat diambil dari penelitian ini, yaitu:

1. Jika kendaraan rencana berupa mobil penumpang, maka kecepatan rencana dan lebar badan jalan sesuai dengan kriteria fungsi jalan berdasarkan Pd.T 18-2004-B Penentuan Klasifikasi Fungsi Jalan di
Kawasan Perkotaan.

2. Jari-jari putar, jarak pandang masuk, dan pola lintasan bus tidak sesuai dengan yang disyaratkan oleh pedoman Pt.T 02-2002-B Tata Cara Perencanaan Geometrik Persimpangan Sebidang dan Tata Cara Perencanaan Geometrik Jalan antar Kota No. 038/TBM/1997. 
Saran yang dapat diberikan dari penelitian ini, yaitu:

1. Perlu dilakukan perbaikan jari-jari putar, jarak pandang masuk, dan pola lintasan pada Simpang Jl. Dipatiukur - Jl. Hasanuddin agar sesuai dengan yang disyaratkan untuk kendaraan rencana berupa bus.

2. Perlu dilakukan penertiban terhadap on-street parking dan pedagang kaki lima agar kecepatan kendaraan meningkat.

\section{DAFTAR PUSTAKA}

[1] __ (1990): Tata Cara Pelaksanaan Survai Inventarisasi Jalan dan Jembatan Kota No. 017/T/BNKT/1990, Direktorat Pembinaan Jalan Kota, Direktorat Jenderal Bina Marga, Departemen Pekerjaan Umum, Jakarta.

[2] __ (1997): Tata Cara Perencanaan Geometrik Jalan antar Kota No. 038/TBM/1997, Direktorat Jenderal Bina Marga, Departemen Pekerjaan Umum, Jakarta.

[3] _ (2002): Pt.T 02-2002-B Tata Cara Perencanaan Geometrik Persimpangan Sebidang,
Departemen Permukiman dan Prasarana Wilayah, Jakarta.

[4] (2004): Pd.T 18-2004-B Penentuan Klasifikasi Fungsi Jalan di Kawasan Perkotaan, Departemen Permukiman dan Prasarana Wilayah, Jakarta.

[5] (2004): UU Republik Indonesia No. 38 tahum 2004 tentang Jalan, Pemerintah Republik Indonesia, Jakarta.

[6] __ (2009): UU Republik Indonesia No. 22 tahun 2009 tentang Lalu Lintas dan Angkutan Jalan, Pemerintah Republik Indonesia, Jakarta.

[7] __ (2015): Bandung dalam Angka, Badan Pusat Statistik Kota Bandung, Bandung.

[8] Iskandar, H. (2008): Volume Lalu Lintas Rencana untuk Geometrik dan Perkerasan Jalan, Jurnal Puslitbang Jalan dan Jembatan, Bandung.

[9] Kusnandar, E. (2008): Dimensi Kendaraan Rencana yang Operasional, Jurnal Puslitbang Jalan dan Jembatan, Bandung. 